1 ESD1 Affects Seed Setting Rate in Rice by Controlling Embryo Sac

\title{
Development $^{1}$
}

Tiankang Wang,b, Yixing Li ${ }^{\mathrm{a}}$, Shufeng Song ${ }^{\mathrm{a}}$, Mudan Qiu ${ }^{\mathrm{a}}$, Licheng Zhang ${ }^{\mathrm{b}}$, Chengxia $\mathrm{Li}^{\mathrm{a}}$, Hao Dong ${ }^{\mathrm{a}}$, Lei $\mathrm{Li}^{\mathrm{b}}$, Jianlong Wang ${ }^{\mathrm{b}, 2}, \mathrm{Li} \mathrm{Li}^{\mathrm{a}, 2,3}$

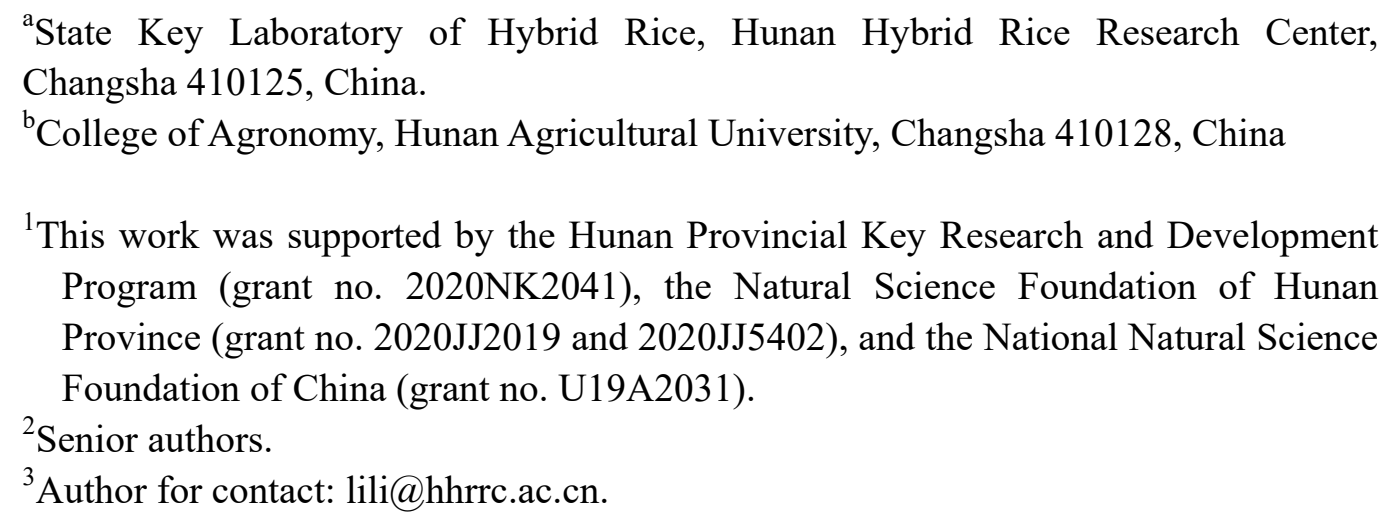

${ }^{1}$ This work was supported by the Hunan Provincial Key Research and Development Program (grant no. 2020NK2041), the Natural Science Foundation of Hunan Province (grant no. 2020JJ2019 and 2020JJ5402), and the National Natural Science Foundation of China (grant no. U19A2031).

${ }^{2}$ Senior authors.

${ }^{3}$ Author for contact: lili@hhrrc.ac.cn.

L.L., and J.W. designed the research process, and revised the paper; T.W., YL., SS., MQ., LZ., CL., HD., and Lei.L. performed the experiments, and drafted the manuscript.

The author responsible for the distribution of materials integral to the findings presented in this article in accordance with the policy described in the instructions for authors (www.plantphysiol.org) is: Li Li (lili@hhrrc.ac.cn).

Abstract: Seed setting rate is one of the critical factors that determine rice yield. Grain formation is a complex biological process, whose molecular mechanism is yet to be improved. Here we investigated the function of an OVATE family protein, Embryo Sac Development 1 (ESD1), in the regulation of seed setting rate in rice (Oryza sativa) by examining its loss-of-function mutants generated via CRISPR/Cas9 technology. ESD1 was predominantly expressed at stage 6 of panicle development, especially in the ovules. esd1 mutants displayed reduced seed setting rates with normal stamen development and pollen tube growth but abnormal pistil group. Investigation of embryo sacs revealed that during the mitosis of functional megaspores, some egg cells degraded during differentiation in esd1 mutants, thereby hindering subsequent fertilization process and reducing seed setting rate. In addition, the transcriptional level of OsAPC6, a reported embryo sac developing gene, was 
found to be significantly reduced in esd1 mutants. These results support that ESD1 is an important modulator of embryo sac development and seed setting rate in rice. Together, this finding demonstrates that ESD1 positively regulates the seed setting rate by controlling embryo sac development in rice, and has implications for the improvement of rice yield.

Key words: rice; ESD1; seed setting rate; embryo sacs

\section{Introduction}

Rice is one of the most important food crops in the world. At present, the controlling mechanism of rice yield has made great progress, particularly in grain weight and effective panicles, but little is known about the seed setting rate. Seed setting rate is affected by several factors, including biomass-spikelet ratio, spikelet-to-leaf ratio, specific leaf weight, spikelet-sheath quantity, and spikelet differentiation (Zhou et al., 2011; Toh et al., 2012; Li et al., 2013; Xu et al., 2017; Liu et al., 2018; He et al., 2019; Liu et al., 2019; Xu et al., 2019; Xiang et al., 2019). Moreover, seed setting rate is also easily affected by the external environment, such as drought, high temperature, low temperature, or saline-alkali stress (Xu et al., 2014; Fu et al., 2014; Wang et al., 2016b; Ma et al., 2018; Cheabu et al., 2018; Si et al., 2018). Further study of seed setting rate has important significance both for its mechanism and for the improvement of rice yield.

As an essential part of spikelet, embryo sac development can directly affect seed setting rate. The development of rice embryo sacs can be divided into two stages, the first stage involves the formation of functional megaspores, in which the megasporocyte undergoes meiotic division to yield four haploid cells, three of which disappear, while one becomes the functional megaspore, the second stage is the formation of embryo sac, in which the functional megaspores undergo mitosis three times and eventually form a mature embryo sac, there have been some reports about genes related to embryo sac development (Zee 1997; Li et al., 2007; Chang et al., 2009; Wang et al., 2012; Hou et al., 2019; Khanday et al., 2019; Wang et al., 2019; $\mathrm{Xu}$ et al., 2020). OsRAD51C, which belongs to the RecA/RAD51 family, is associated with the normal meiotic division of megasporocyte and microsporocyte at 
an early stage (Kou et al., 2012; Tang et al., 2014). OsMSH4 and OsMSH5, the members of the ZMM family, can form a heterodimer, which plays a critical role in the regulation of homologous chromosome exchange in the meiotic division (Luo et al., 2013; Zhang et al., 2014). Especially, OsMSH4 influences the exchange of homologous chromosomes during meiotic division of male and female (Wang et al., 2016a). The OsAPC6 gene encodes an APC6 protein, affecting the development of female gametes but not the development of male gametes. OsAPC6 is crucial for the smooth transition from mitosis metaphase to mitosis anaphase. The T-DNA inserted osapc6 mutants are fertile in males and partially sterile in females. The plants exhibit dwarfed, and their seed setting rates are reduced by 45\% (Kumar et al., 2010; Awasthi et al., 2012).

The OVATE family proteins (OFP) are plant-specific proteins with a conserved OVATE domain (Liu et al., 2014). The discovery of OFP protein family originated from the gene OVATE which regulates the shape of tomato fruit. The C-terminal of OVATE protein contains a highly conserved OVATE domain (Liu et al., 2002). The genes of OFP protein family are widely presented in various plant species such as Arabidopsis (Arabidopsis thaliana), rice (Oryza sativa), tomato (Solanum lycopersicum), and pepper (Capsicum annuum). OFP family proteins play a key role in regulating the growth and development of plants, including the construction of fruit shape, fruit maturity and quality formation, DNA repair, vascular bundle development, secondary cell wall formation, and embryo sac development (Hackbusch et al., 2005; Wang et al., 2008; Pagnussat et al., 2007; Wang et al., 2010; Li et al., 2011a; Toh et al., 2012; Schmitz et al., 2015; Yang et al., 2016; Ma et al., 2017; Xiao et al., 2017).

In our previous study, microarray data showed that ESD1 protein belongs to the OFP family was highly and abundantly expressed mainly in spikes. In this study, we find that ESD1 positively regulates the rice seed setting rate by controlling embryo sac development. Its loss-of-function esd1 mutants were successfully generated via CRISPR/Cas9 technology. Results showed that esd1 mutants exhibited abnormal development of embryo sac, thereby ultimately decreasing the seed setting rate. Meanwhile, the transcriptional level of OsAPC6, an embryo sac development related gene, was found to be significantly reduced in esd1 mutants. ESD1 had the highest level of expression at stage 6 of young panicle development, especially in the ovules, 
97 and ESD1-GFP fusion proteins predominantly localized in cytoplasm. Our results 98 support ESD1 as a key modulator of rice seed setting rate. This finding has 99 significance for the improvement of rice yield.

100

101 


\section{Results}

\section{ESD1 belongs to the OFP family}

104 ESD1 contains only one exon without intron, and its predicted protein ESD1 has 253 amino acids (aa). The SMART database (Simple Modular Architecture Research Tool, http://smart.embl-heidelberg.de/) showed that ESD1 contains an OVATE domain located at 164-227 aa, and belongs to the OFP family (Hackbusch et al., 2005; Liu et al., 2014) (Fig. 1A). The OFP family has 33 members in rice (from OsOFP1 to OsOFP33), and ESD1 is numbered OsOFP31 (Liu et al., 2014). The phylogenetic tree constructed according to the amino acid sequences of 33 members showed that the homological differences between members are relatively significant. ESD1 shares the closest homology with OsOFP7 and is also close to OsOFP27 and OsOFP8 (Fig. 1B). qRT-PCR showed that the expression levels of ESD1 in roots, stems and leaves were very low, and there was a parabolic curve at stages 3-8 of young panicle development. The expression levels at stages 3-6 of panicle development gradually increased, 116 peaked at stage 6 , followed by a plunge at stage 7 , and reached the lowest point at 117 stage 8 (Fig. 1C). The roots, stems and leaves at the panicle differentiation stage as 118 well as the young panicles at stages 3-8 were used for in situ hybridization. The results showed that the strongest hybridization signals of ESD1 presented at stage 6 of panicle development, which mainly distributed in the ovules (Fig. 1, D-H). The results of in situ hybridization were consistent with those of qRT-PCR, indicating that ESD1 functions in ovules at the panicle development process in rice. 


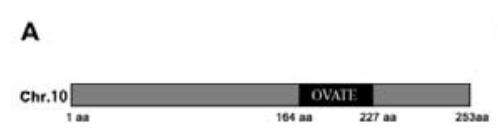

B

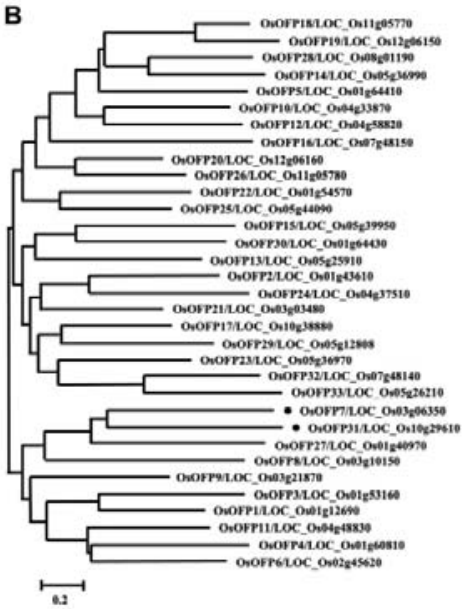

A

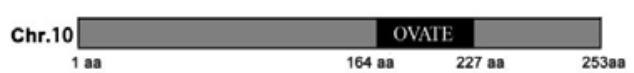

B

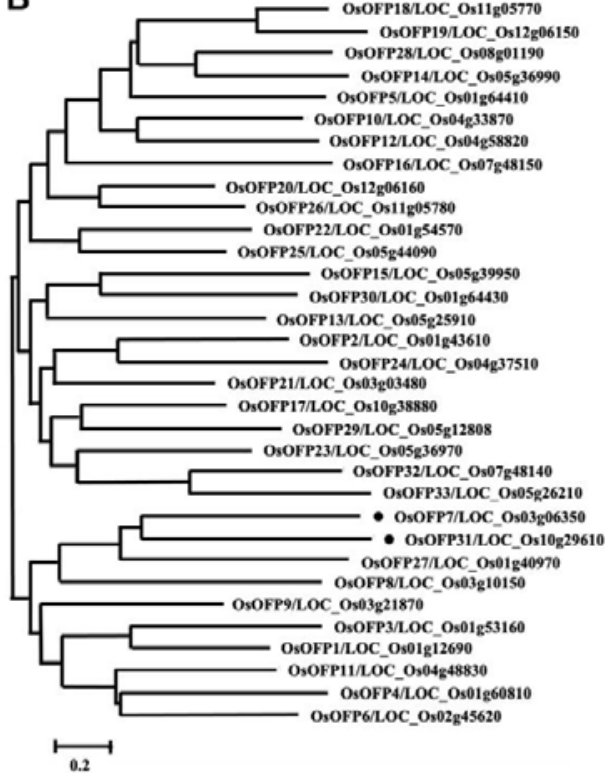

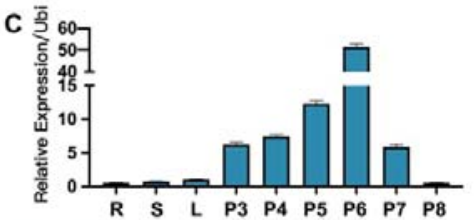
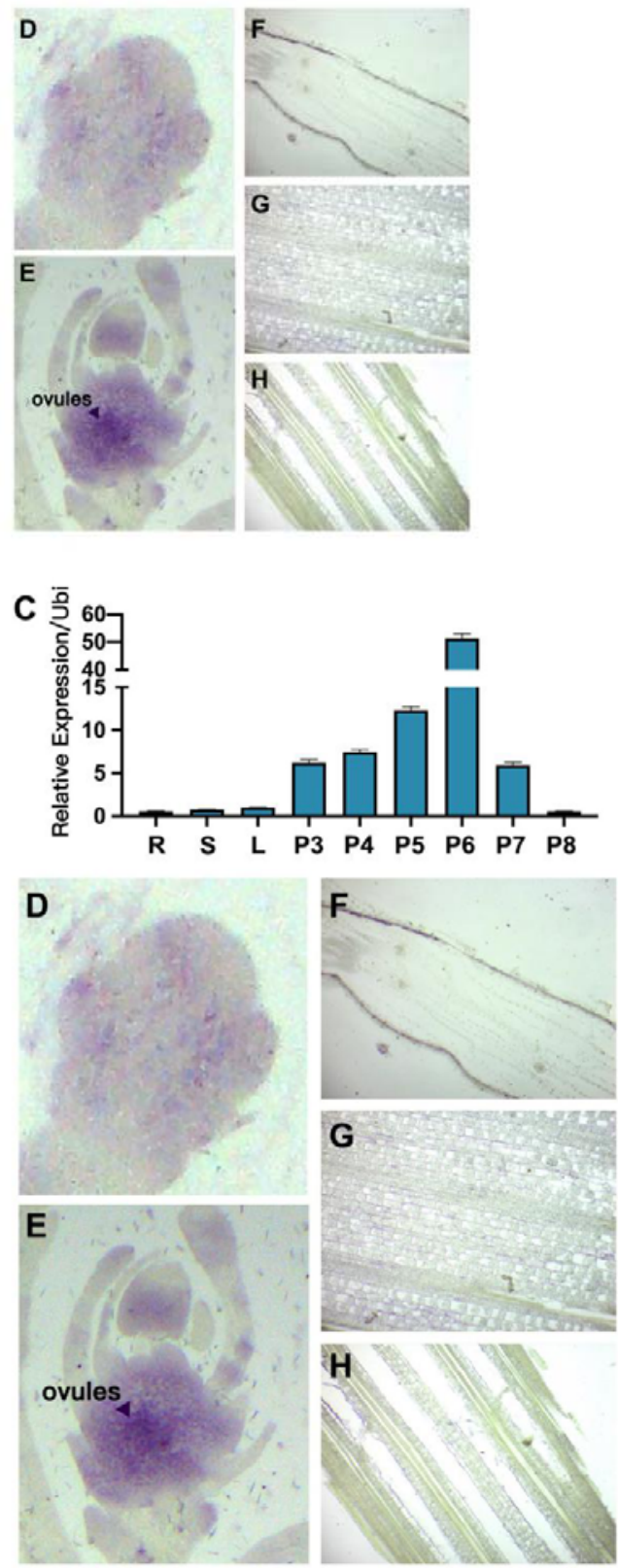

H

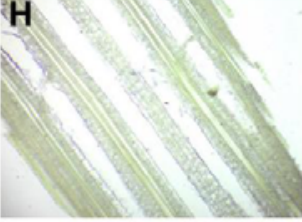

Figure 1. Gene structure and expression patterns of ESD1. A, Structural pattern diagram of ESD1. B, Phylogenetic tree of OFP family members. C, ESD1 expressions in roots, stems, leaves, and young panicles at stages 3-8; R, roots; S, stems; L, leaves; P3-P8, young panicles at stages 3-8. D, In situ hybridization of ESD1 at stage 3 of panicle development. E, In situ hybridization of ESD1 at stage 6 of panicle development. F, In situ hybridization of ESD1 in roots. G, In situ hybridization of ESD1 in stems. H, In situ hybridization of ESD1 in leaves. 
The recombinant vector $p G B K T 7-E S D 1$ was transferred into yeast (Saccharomyces cerevisiae) strain Y2HGold. The strain expressing ESD1 proteins could not grow on the systematic tri-deficient medium (Fig. 2A), indicating that ESD1 was inactive in transcriptional activations. The ESD1 and GFP fusion expression vector was transferred into rice protoplasts. The fluorescent signals of ESD1-GFP fusion proteins were mainly distributed in the cytoplasm (Fig. 2B).

A

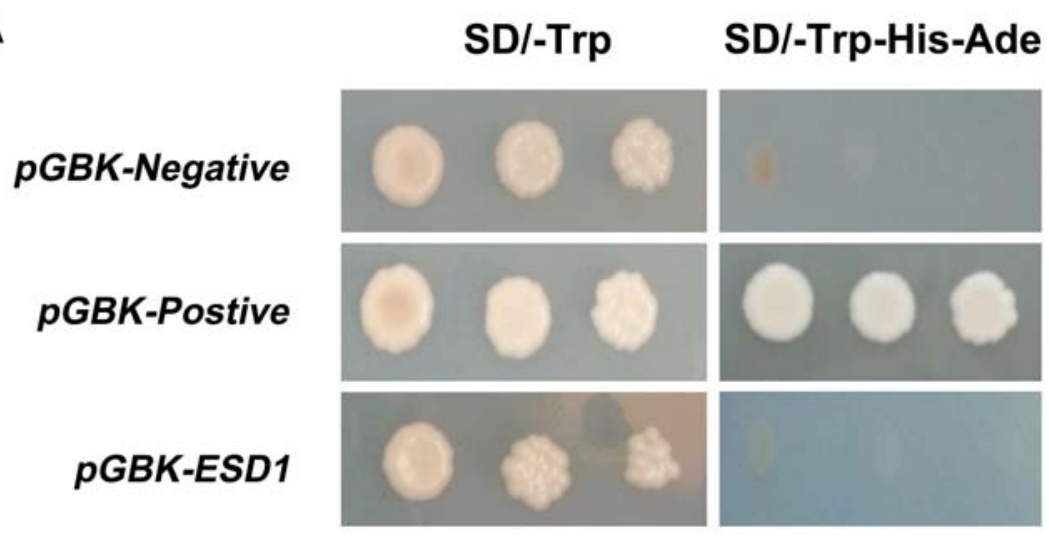

B

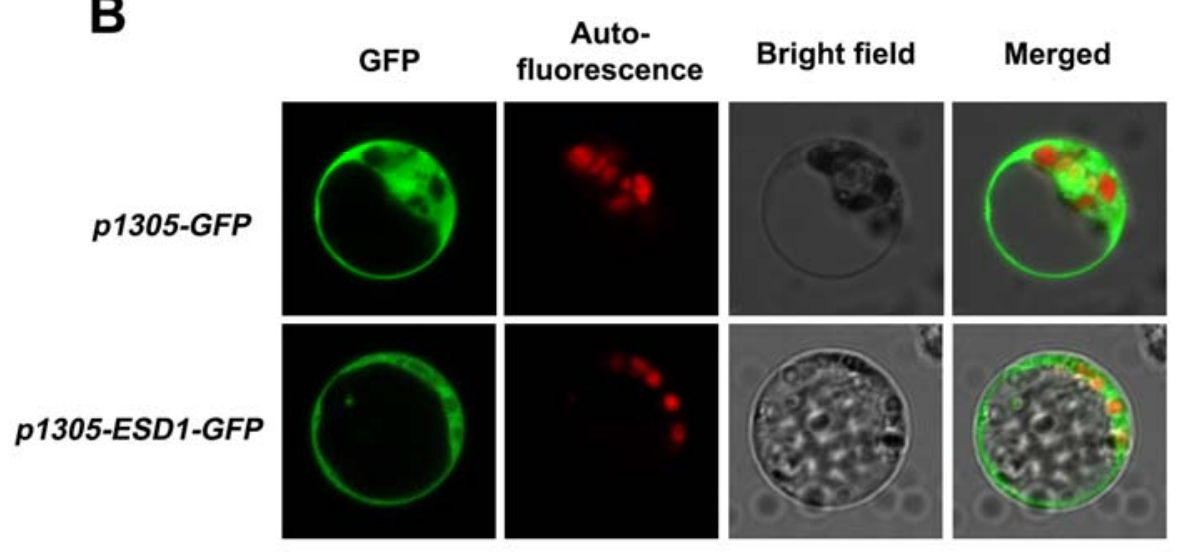

Figure 2. Protein subcellular localization of ESD1. A, Verification of ESD1 transcription activation. B, Subcellular localization of ESD1 in rice protoplasts. 


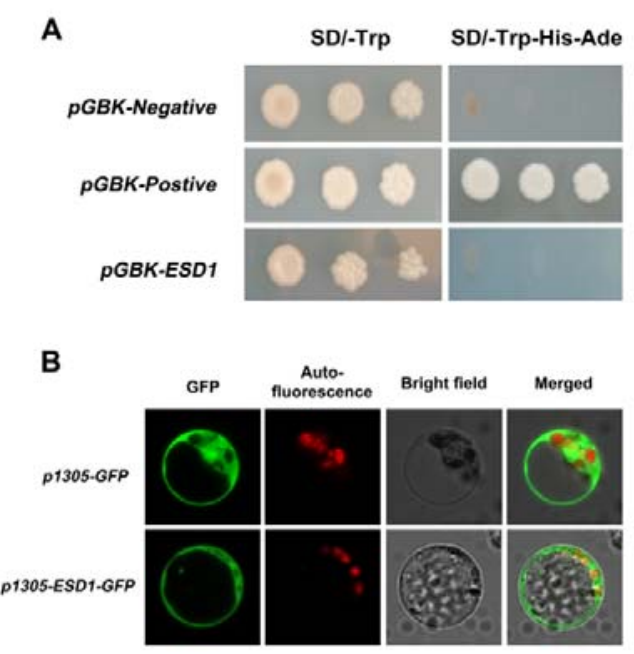

In this study, two targeted editing sites (TS1 and TS2) of ESD1 were constructed onto the CRISPR/Cas9 based binary expression vector (Fig. 3A). The calli induced from a japonica rice 9522 were infected with the Agrobacterium-mediated transformation process and subjected to tissue culturing, resulting in two edited homozygous mutants esd1-m1 and esd1-m2 as well as a heterozygous mutant esd1-m3 (Fig. 3, B and C). The mutant esd1-m1 was inserted with $\mathrm{G}$ and $\mathrm{T}$ at TS1 and TS2, respectively, resulting in an alteration of translated protein sequence after 71 aa, and an early termination after 91 aa, which caused the missing structure of the OVATE domain. The mutant esd1-m2 was inserted with A at TS1 and deleted a sequence of AGTCGATGA at TS2, resulting in a change of translated protein sequence after 72 aa and an early termination after 91 aa, which also caused the missing structure of the OVATE domain. As for the heterozygous mutant esd1-m3, ESD1 of one chromosome was normal, while ESD1 of the other homologous chromosome was inserted with G at TS2, resulting in the translation of two types of protein, one of which was normal ESD1 protein, the other changed after 174 aa, which also caused the missing structure of the OVATE domain (Fig. 3D). 


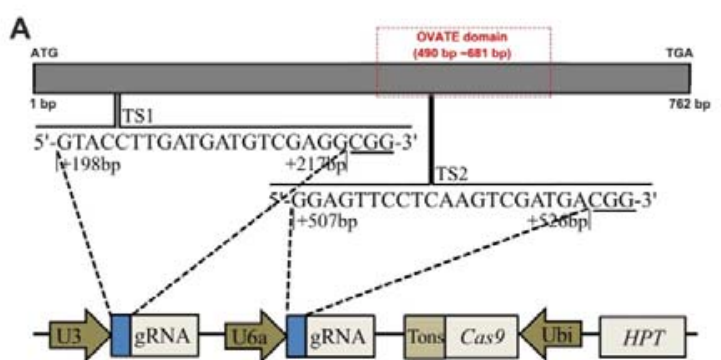

D

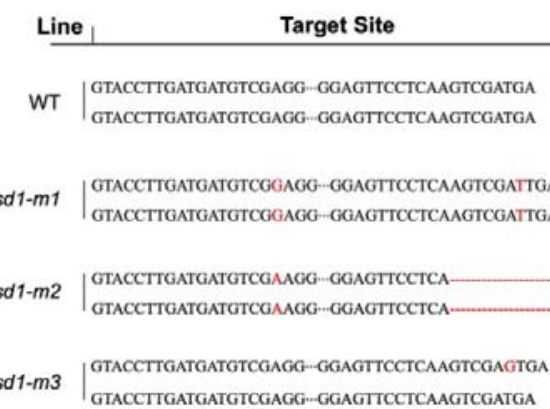

A $_{\text {ATG }}$

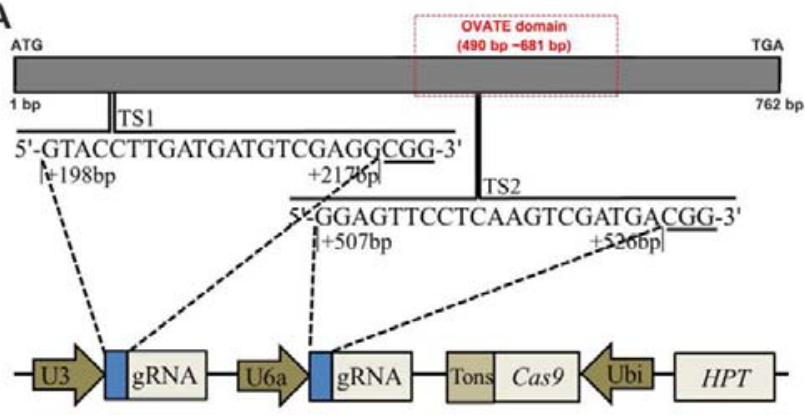

D

Line $\_$Target Site

esd1-m1 | GTACCTTGATGATGTCGGAGG‥GGAGTTCCTCAAGTCGATTGA

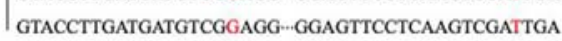

esd1-m2 $\begin{aligned} & \text { GTACCTTGATGATGTCGAAGG-GGAGTTCCTCA } \\ & \text { GTACCTTGATGATGTCGAAGG‥GGAGTTCCTCA }\end{aligned}$

esd1-m3

GTACCTTGatgatgTCGAGG...GGAGTTCCTCAaGTCGAGTGA GTACCTTGATGATGTCGAGG-..GGAGTTCCTCAAGTCGATGA

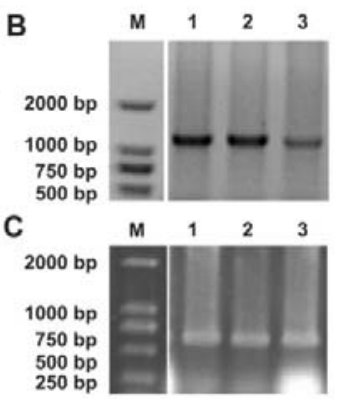

250 bp
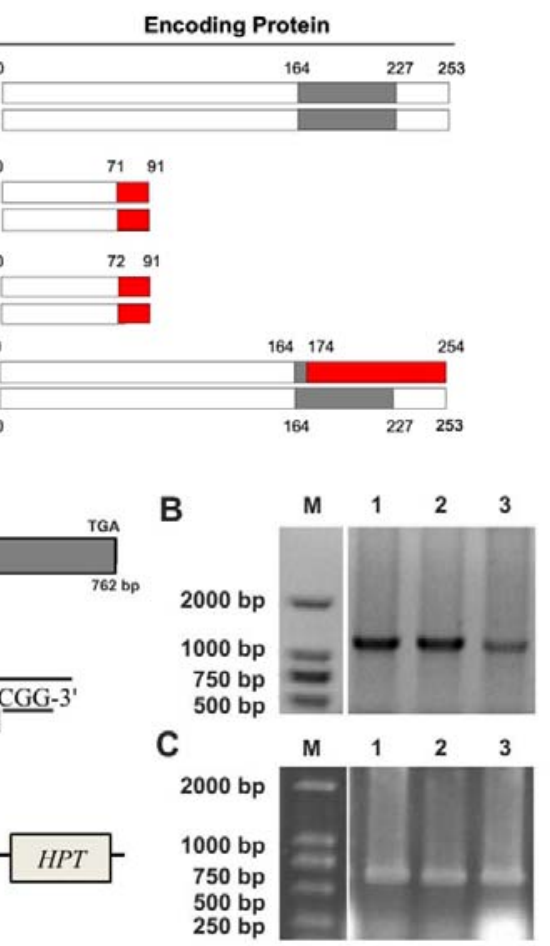

Encoding Protein
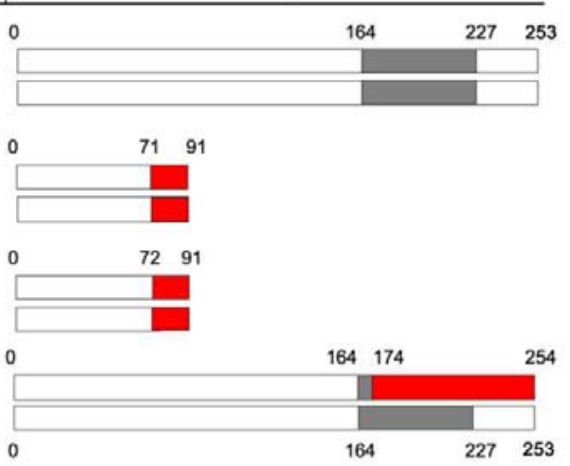

Figure 3. Targeted editing sites and types of mutations. A, Two targeted editing sites, TS1 and TS2, and information on CRISPR/Cas9 recombinant vector element. B, Screening of transgenic plants that integrate gene edited related sequence of the recombinant vector into the 9522 genome by PCR. C, Amplify the TS1 and TS2 sequences of transgenic plants by 
PCR. D, ESD1's mutation types and translated protein residues. The grey box represents the OVATE domain, the red box represents the new amino acid sequence.

Phenotypic analysis indicated that no obvious difference was observed in the plant morphologies and internal spikelet structure between the wild type 9522 and the mutants esd1-m1 and esd1-m2 (Fig. 4A). Similar to 9552, $\mathrm{I}_{2}-\mathrm{KI}$ staining assay showed that the anthers of esd1-m1 and esd1-m2 were fertile (Fig. 4, C-H). Plant height, spikelets per panicle, 1000-grain weight, and tiller number of esd1-m1 and esd1-m2 were not significantly different from those of 9522 (Fig. 4, I, J, L, and M). However, esd1-m1 and esd1-m2 showed a phenotype with decreased seed setting rates, 53\% and $58 \%$, respectively, while that of the 9522 was $84 \%$ (Fig. 4, B, K), indicating that the deficiency of ESD1 mainly reduced the spikelet fertility in rice. Meanwhile, the grain yield per plant of esd1-m1 and esd1-m2 also markedly decreased compared to that of 9522 (Fig. 4N). Whereas, no significant difference was detected in seed setting rates between esd1-m3 and 9522. The population of $\mathrm{T}_{1}$ generation of esd1-m3 showed a separation with seed setting rate. The result of co-segregation experiment showed that 86 single plants (heterozygous mutants and wild type plants) had normal seed setting rates, while 28 single plants (homozygous mutants named esd1-m3h) had reduced seed setting rates (Supplemental Fig. S1). Therefore, the phenotype with seed setting rate was controlled by ESD1. 
bioRxiv preprint doi: https://doi.org/10.1101/2021.02.01.429182; this version posted February 2, 2021. The copyright holder for this preprint (which was not certified by peer review) is the author/funder. All rights reserved. No reuse allowed without permission.
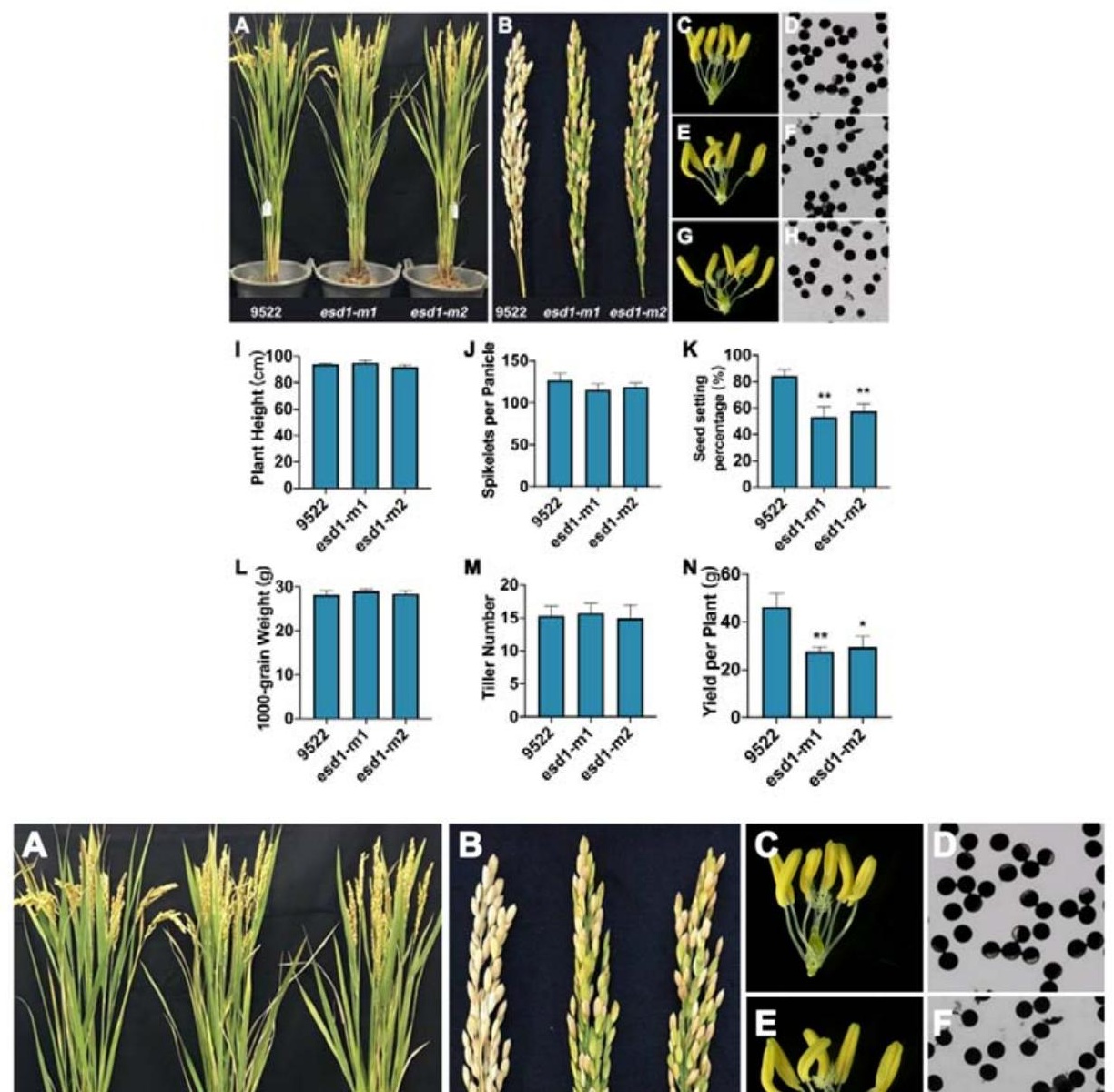
Figure 4. Phenotype identification of esd1 mutants. A, Plant morphology of esd1 mutants. B, Panicle types of esd1 mutants. C, Anthers of 9522. D, Microscopy of 9522 pollen grains. E, Anthers of esd1-m1. F, Microscopy of esd1-m1 pollen grains. G, Anthers of esd1-m2. H, Microscopy of esd1-m2 pollen grains. I, Plant height of esd1 mutants. J, Spikelets per panicle of esd1 mutants. K, Seed setting rate of esd1 mutants. L, 1000-grain weight of esd1 mutants. $\mathrm{M}$, Tiller number of esd1 mutants. N, Yield per plant of esd1 mutants. Asterisks indicate significant difference by Student's $t$ test $\left({ }^{*} P<0.05\right.$ and $\left.{ }^{* *} P<0.01\right)$.

\section{Stamen development and pollen tube growth of esd1 mutants were normal}

Spikelet samples were taken at stage 8 of panicle development from 9522, esd1-m1 and esd1-m2, and fixed with FAA fixative to prepare paraffin sections. The results showed that 9522, esd1-m1 and esd1-m2 had no significant differences in the structure of anthers, and all pollen grains were fertile (Fig. 5, A-C). Pollen grains were collected from 9522, esd1-m1 and esd1-m2 before flowering and cultured in vitro. The results showed that the germination rate of 9522 was $73.1 \%$, while those of esd1-m1 and esd1-m2 were $72.0 \%$ and $71.1 \%$, respectively, indicating that no significant differences was detected in the germination rates among the three genetic lines (Fig. 5, D-F). Spikelet samples at different stages after flowering were collected from 9522, esd1-m1 and esd1-m2. The elongation process of pollen tubes was observed using an aniline blue staining. The results showed that the anthers of 9522 , esd1-m1 and esd1-m2 could split open normally upon maturity. Their pollen grains could normally adhere to the stigma (Fig. 5, G-I), germinate pollen tubes along the styles, and eventually enter the embryo sac through the ovule hole (Fig. 5, J-L). These results indicated that the stamen development and pollen tube growth of esd1 mutants were normal. 
bioRxiv preprint doi: https://doi.org/10.1101/2021.02.01.429182; this version posted February 2, 2021. The copyright holder for this preprint (which was not certified by peer review) is the author/funder. All rights reserved. No reuse allowed without permission.
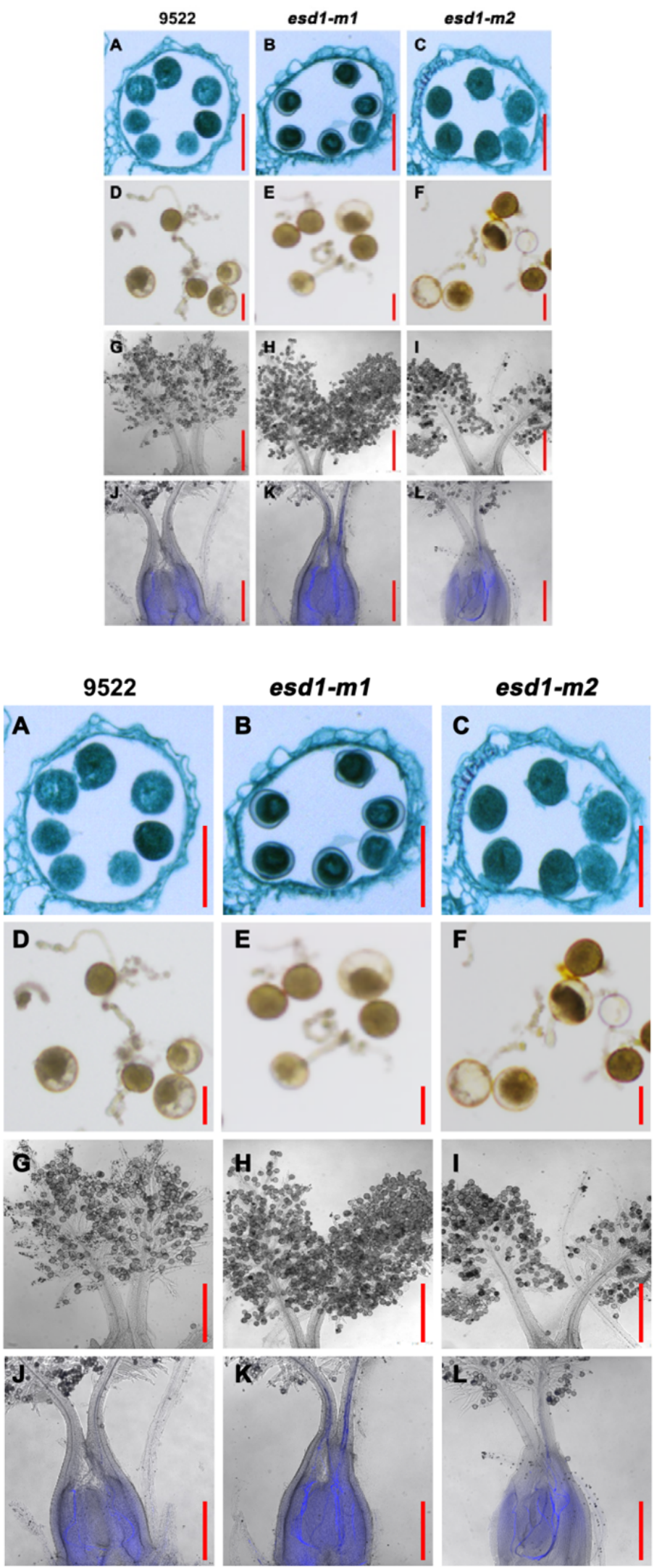
Figure 5. Microscopy of pollen grains and pollen tubes of esd1 mutants. A to C, Anther paraffin sections of 9522, esd1-m1 and esd1-m2. D to F, Pollen grain germinations in vitro of 9522, esd1-m1 and esd1-m2. G to I, Pollen grains of 9522, esd1-m1 and esd1-m2 attached to the stigmas. $\mathrm{J}$ to L, Pollen tube growth of 9522, esd1-m1 and esd1-m2 (bright field microscopy + fluorescence microscopy).

\section{The pistil group of esd1 mutants was abnormal}

$\mathrm{I}_{2}$-KI staining was performed on the spikelets of 9522, esd1-m1 and esd1-m2 after flowering, and transparent xylene was used to examine the fertilization of spikelets. The results showed that the fertilization rate of 9522 was significantly higher than those of esd1-m1 and esd1-m2 (Fig. 6, A-D). The main panicles of esd1-m1 were then subjected to natural pollination and saturated pollination. The results showed that the seed setting rate of esd1-m1 natural pollination and saturated pollination were $61 \%$ and $64 \%$, respectively, which have no significant difference (Fig. 6E). When the panicles of de-tasseled 9522's main panicles were pollinated with esd1-m1 pollens, the resulted seed setting rate of 9522 was $81 \%$. However, when panicles of de-tasseled esd1-m1's main panicles were pollinated with 9522 pollens, the seed setting rate of esd1-m1 was $54 \%$ (Fig. $6 \mathrm{~F}$ ). These results further indicated that the anther development of esd1 mutants was normal, and the cause of decreased seed setting rate of esd1 mutants was affected by pistil group and occurred before fertilization.
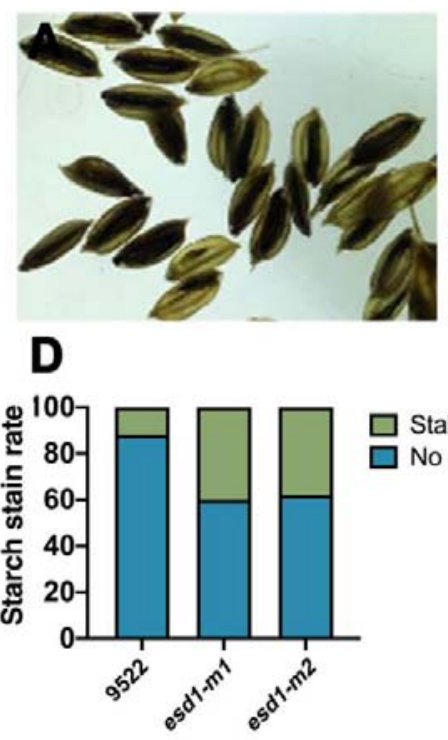
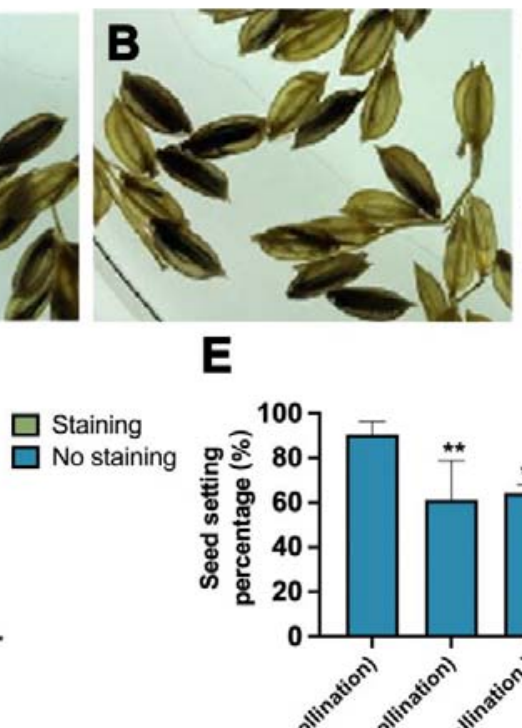

E

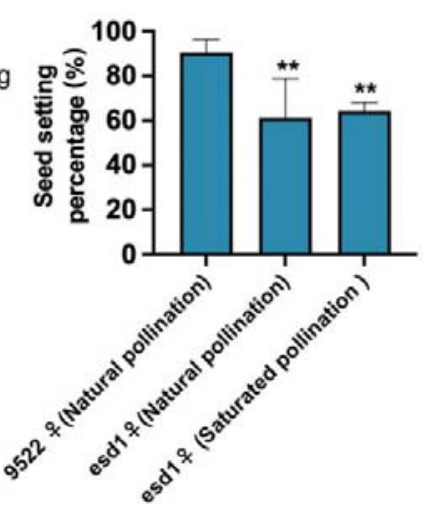

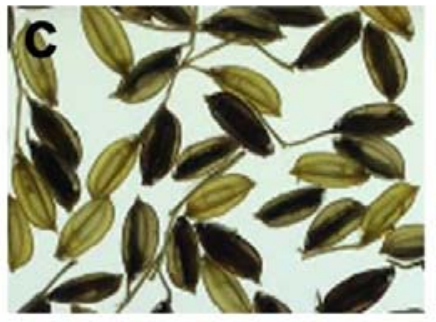

$\mathbf{F}$

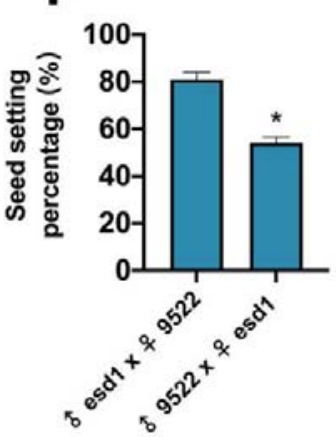




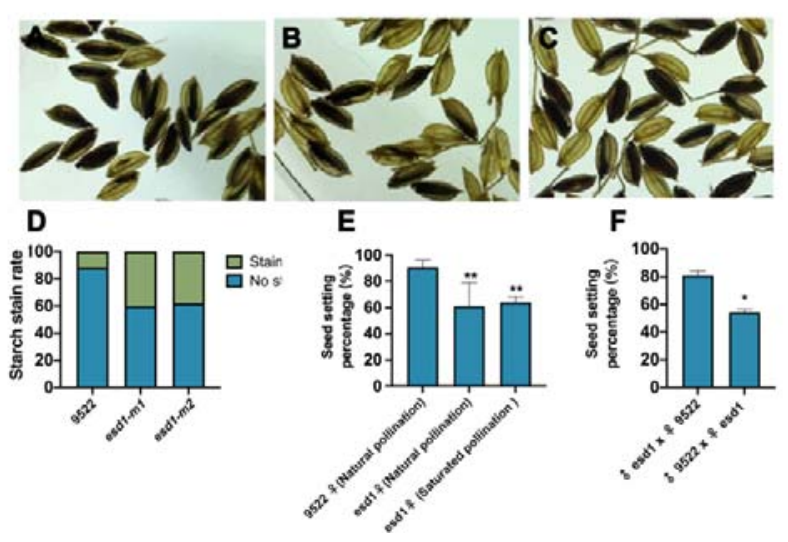

Figure 6. Fertilization and hybridization detection of esd1 mutants. A to C, Embryo sac fertilization results of 9522, esd1-m1 and esd1-m2. D, Starch stain rate of 9522, esd1-m1 and esd1-m2. E, Natural pollination of esd1 mutants and saturation pollination of esd1 mutants with 9522 pollens. F, Reciprocal crosses between 9522 and esd1-m1. Asterisks indicate significant difference by Student's $t$ test $\left({ }^{*} P<0.05\right.$ and $\left.{ }^{* *} P<0.01\right)$.

\section{No egg cells were detected in the partially matured embryo sacs of esd1 mutants}

A large number of mature embryo sacs of 9522, esd1-m1 and esd1-m2 were stained with nuclear-specific fluorescent dyes and hyalinized using hyalinization techniques. Samples were then scanned and photographed at $2 \mu \mathrm{m} /$ layer under a confocal laser scanning microscope. The mature embryo sacs of 9522 were tested first, and $92 \%$ of their embryo sacs were found to develop healthily with a "seven cells and eight nuclei" structure at different levels of definition (Fig. 7, A and D). The mature embryo sacs of esd1-m1 were then observed, and $58 \%$ of their embryo sacs developed normally, whereas $42 \%$ failed to show any egg cells and synergids despite the existence of normal antipodal cells and central polar nuclei (Fig. 7, B and D). Similarly, among the embryo sacs of esd1-m2, 56\% developed normally, whereas $44 \%$ showed no egg cells and synergids (Fig. 7, C and D). The transcriptional levels of genes involved in the development of rice embryo sac were detected in the young panicles of 9522 and esd1 mutants by qRT-PCR. The results showed that the deficiency of ESD1 could significantly reduce the expression of OsAPC6 (Fig. 7E). These results demonstrated that abnormal development of some embryo sacs led to a reduction in seed setting rates in esd1 mutants. 

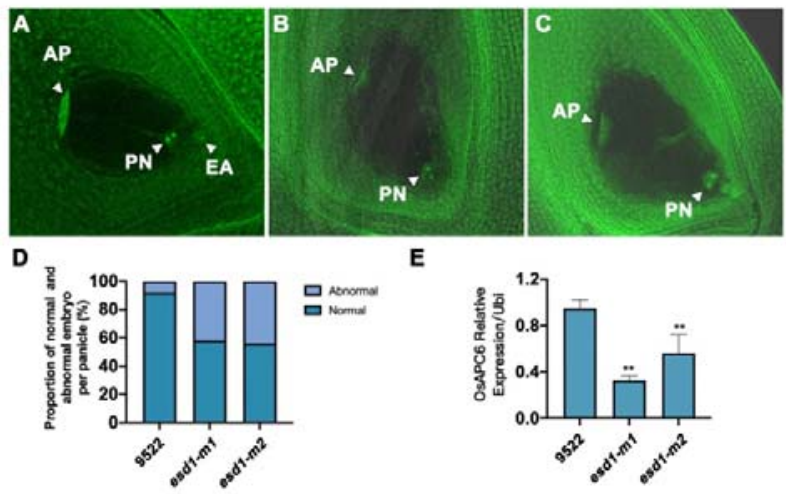

믐 Nomamat

E
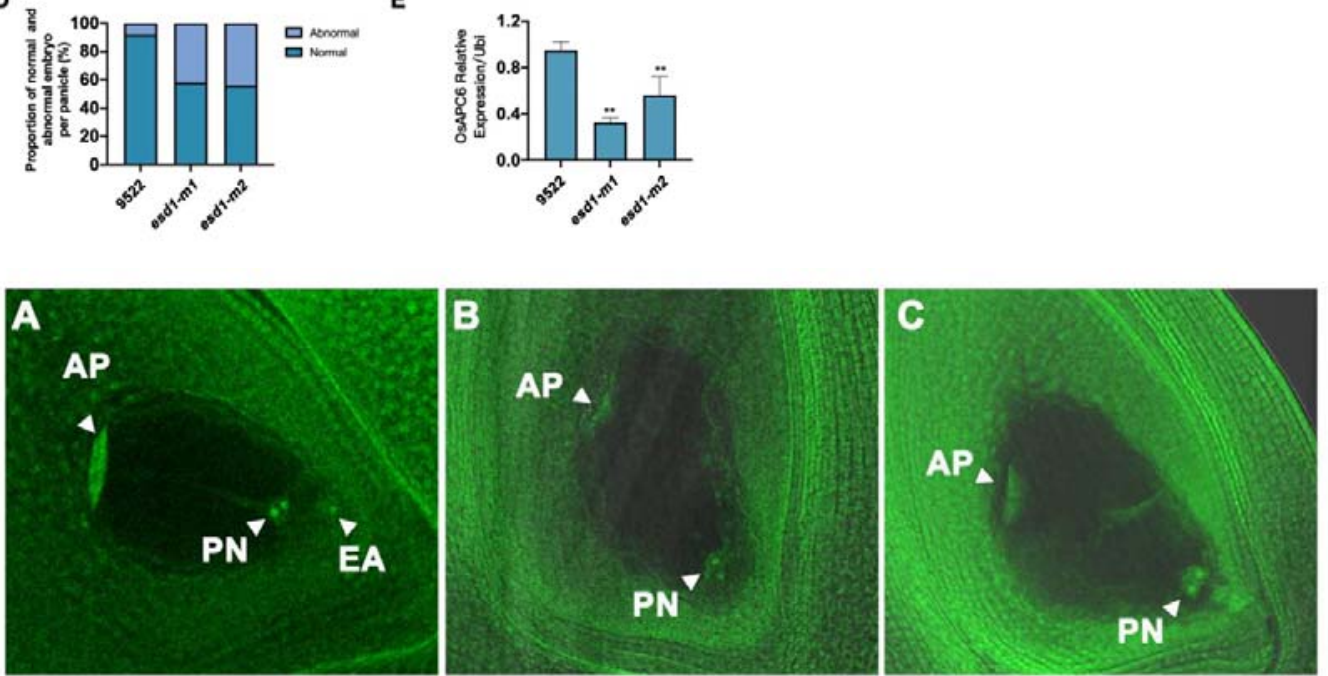

$\mathbf{E}$

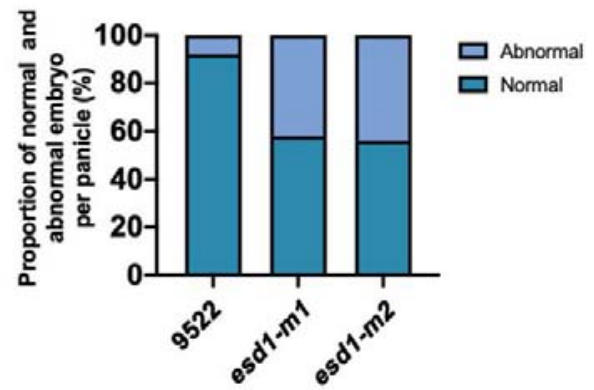

Figure 7. Detection of mature embryo sac of esd1 mutants and related qRT-PCR. A, Normal embryo sac of 9522; AP, antipodal cells; PN, polar nuclei; EA, egg cell. B, Abnormal embryo sac of esd1-m1. C, Abnormal embryo sac of esd1-m2. D, Abnormal embryo sac ratio of esd1 mutants. E, Expression of OsAPC6 in the young panicles of 9522 and esd1 mutants. Asterisks indicate significant difference by Student's $t$ test $(* * P<0.01)$.

\section{The ubiquitin-mediated protein degradation pathway was the most involved} metabolic pathway in esd1 mutant differentially expressed genes 

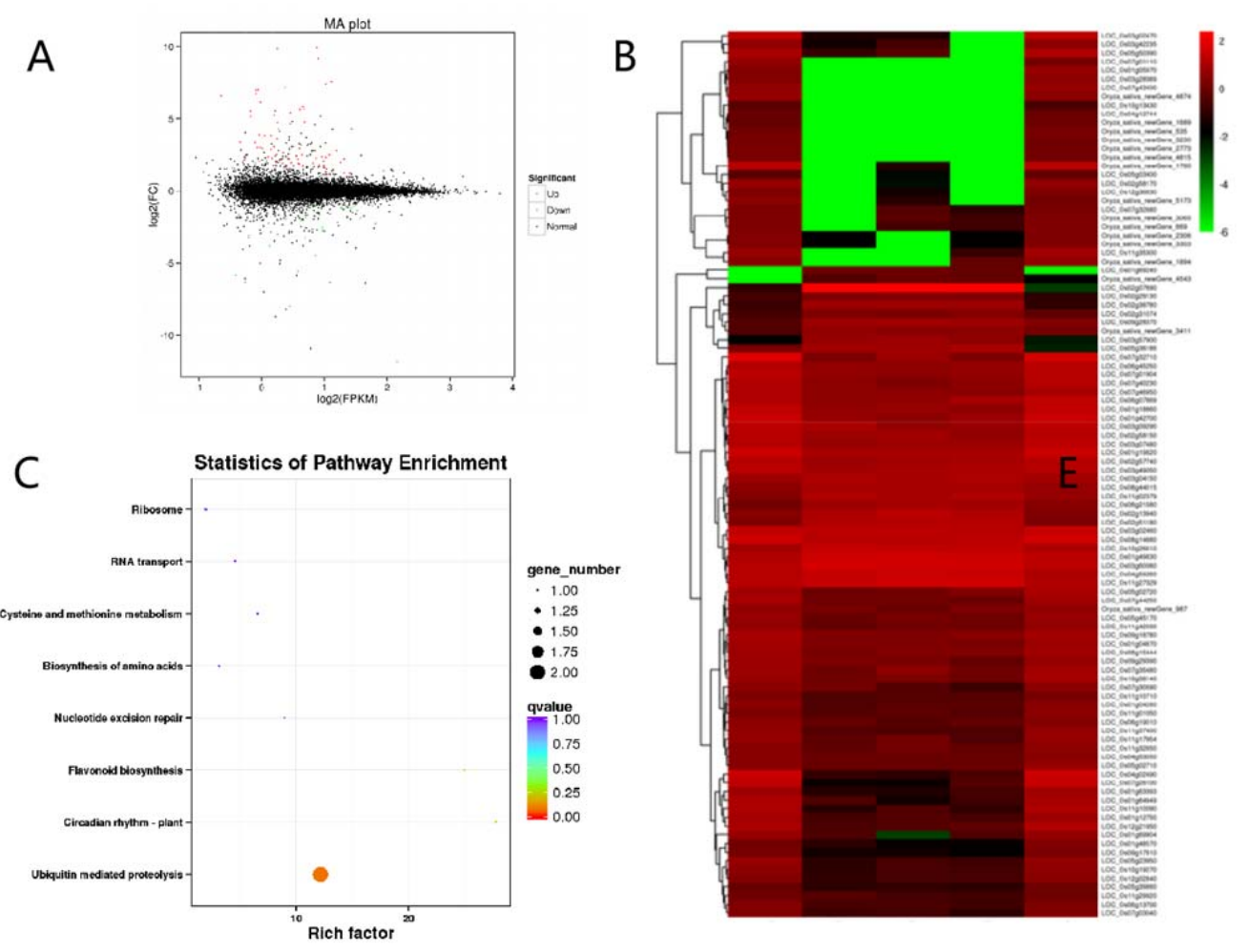

The young panicles at stages 5 and 6 of panicle development of 9522 and esd1-m1 were taken to transcriptome analysis. A total of 190 significant differentially expressed genes (DEGs) were detected, and 51 common DEGs were presented at two stages. One hundred and two significant DEGs were detected in esd1-m1 with 81 up-regulated and 21 down-regulated expression genes at stage 5. A total of 88 significant DEGs, 72 up-regulated and 16 down-regulated genes, were detected in esd1-m1 at stage 6 (Fig. 8A). The results of hierarchical cluster analysis showed that DEGs of 9522 and esd1-m1 could cluster together at stage 5, indicating a high degree of similarity in genetic background and gene expression patterns between 9522 and esd1-m1 (Fig. 8B). One hundred and ninety DEGs were classified into eight functional categories, namely ubiquitin mediated proteolysis, circadian rhythm, biosynthesis of amino acids, nucleotide excision repair, flavonoid biosynthesis, cysteine and methionine metabolism, RNA transport and ribosome. The ubiquitin-mediated protein degradation pathway is the most DEGs involved metabolic pathway (Fig. 8C). Meanwhile, the transcriptome analysis also showed that the transcriptional level of OsAPC6 was significantly reduced in esd1-m1, which 
275 was highly consistent with the result of qRT-PCR (Fig. 7E). OsAPC6 was identified to 276 encode a cell cycle-related ubiquitin ligase that degrades mitosis-related regulators via 277 the ubiquitin-proteasome pathway (Kumar et al., 2010). These results imply that the 278 ubiquitin-mediated protein degradation pathway might be involved in regulating the development of embryo sacs in rice.

A

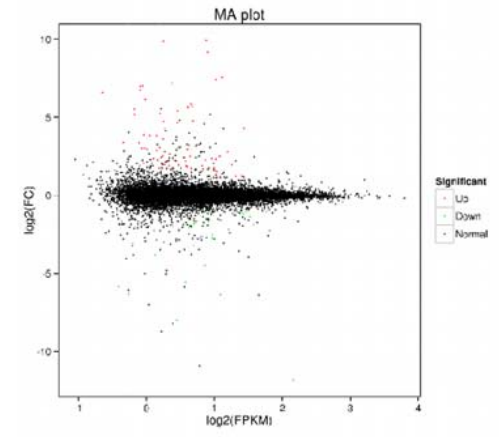

280

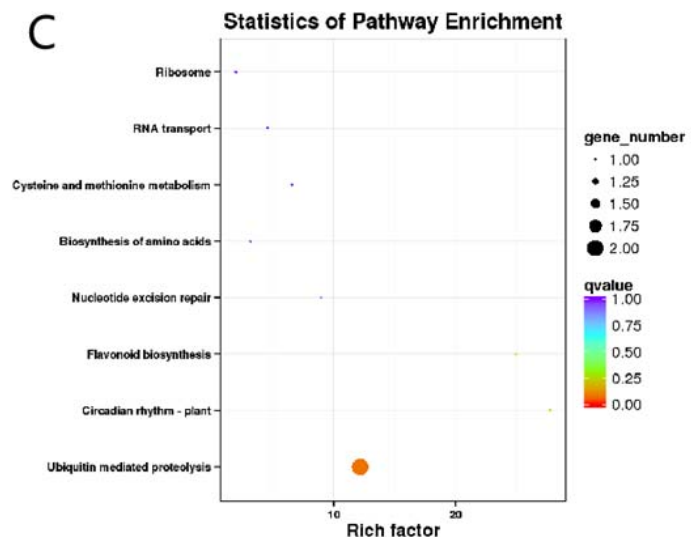

B

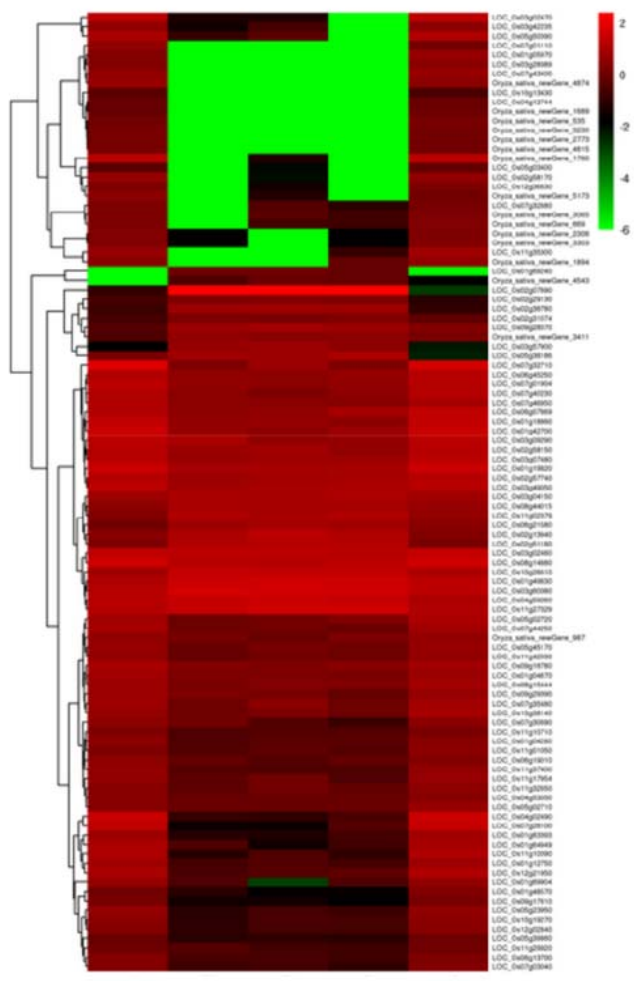

Figure 8. Transcriptome analysis of ESD1. A, Differential expression volcano map. B, Differentially expressed gene cluster map. C, Scatter plot of enrichment of differentially expressed gene KEGG pathway. 


\section{Discussion}

Seed setting rate, grain number and grain weight are the most important factors that determine rice yield. Seed setting rate is affected by several factors including the pistil and stamen development. It has been reported that OFP family members can regulate pistil development. For example, the OFP family member AtOFP5 protein is involved in regulating ovule formation in Arabidopsis (Hackbusch et al., 2005; Pagnussat et al., 2007). In our previous study, microarray data showed that ESD1 protein which contains an OVATE domain located at 164-227 aa and belongs to the OFP family was highly and abundantly expressed mainly in spikes. In this study, we obtained several different types of loss-of-function mutants of ESD1 by CRISPR/Cas9 technology (Ma et al., 2016; Sun et al., 2016; Zhang et al., 2018; Selma et al., 2019; Zhang et al., 2019; Ma et al., 2020). The seed setting rates of esd1 mutants were significantly lower compared to that of wild type 9522, and the co-segregation test showed that the trait was controlled by a single gene. The above research indicated that ESD1 is a key modulator of rice seed setting rate.

Low seed setting rate in rice can be caused by many factors (Zhou et al., 2011; Li et al., 2013; Xu et al., 2019). The pollen fertility $\mathrm{I}_{2}$-KI staining, anther paraffin sections, in vitro culture of pollen grains and pollen tube germination test in vivo all proved that the stamen development and pollen tube growth of esd1 mutants were normal. These results suggest that the reduced seed setting rate of esd1 mutants is not resulted from the development of stamens. Promoter element prediction showed that ESD1 has elements involved in photoresponse, such as ACE, Box 4, G-box, G-Box and GA-motif, etc. (Li et al., 2017). To demonstrate whether the fertility of the esd1 mutants were affected by the environment, the esd 1 mutants were planted under different photoperiods and temperature treatments. The results showed that anther developments of 9522 and esd1 mutants were normal under different photoperiods and temperature treatments (Supplemental Fig. S2, S3), and no significant difference was detected in the seed setting rates of esd1 mutants under various treatments, indicating that the functions of ESD1 were not affected by light or temperature.

The results of embryo sac fertilization, reciprocal cross test, natural pollination and saturation pollination further demonstrated that the anther development of esd1 
mutants was normal, and the reduced seed setting rates of esd1 mutants was resulted from the development of pistil group before fertilization. Mature embryo sac structure inspection proved that the embryo sac abortion of esd1 mutants was caused by the absence of egg cell. The presence of normal polar nuclei and antipodal cells in all aborted embryo sacs further suggested that embryo sac development was normal during the meiosis from megasporocyte and first two mitotic divisions from functional macrospore. During or after the third mitosis of functional megaspores, egg cells and synergids gradually degenerate, and this process is not influenced by light and temperature. The results of both qRT-PCR and in situ hybridization demonstrated that ESD1 expression was highest at the $6^{\text {th }}$ stage of panicle differentiation. Stage 6 is the time when functional megaspores begin to undergo mitosis (Liu et al., 1997). The alteration of ESD1 expression level coincided with the failure of embryo sacs of esd1 mutants, which further indicated that ESD1 regulates embryo sac development by influencing mitosis of functional megaspores.

Transcriptome data analysis revealed differentially expressed genes in esd 1 mutant and wild type material. The ubiquitin-mediated protein degradation pathway was the most involved metabolic pathway in differentially expressed genes in esd1 mutants. The ubiquitin-proteasome system is the major pathway of intracellular protein degradation, involved in more than $80 \%$ of protein degradation (Tokumaru et al., 2017; Zhang et al., 2017; Xia et al., 2020; Majumdar et al., 2020). The intracellular or extracellular ubiquitin proteasome system is likely to be involved in regulating the development of embryo sac by acting on different substrates (Liu et al., 2008; Kumar et al., 2010; Awasthi et al., 2012). Transcriptome analysis showed that the deficiency of ESD1 resulted in the down-regulation of OSAPC6 encoding a cell cycle-related ubiquitin ligase involved in the degradation of mitosis-related regulators via the ubiquitin-proteasome pathway, which was consistent with the qRT-PCR result. In the T-DNA insertion mutant of osapc6, the functional megaspores in some of embryo sacs showed an abnormality during the second mitosis, therefore the seed setting rate of osapc 6 mutants was reduced by $45 \%$. Coincidentally, the seed setting rate of the esd1 mutants also decreased by about 45\%. It is hypothesized that ESD1 has a genetic regulatory relationship with OsACP6, both act simultaneously during mitosis of functional macrospores. Consequently, ESD1 might have some regulatory interactions 
348 with OsAPC6, which could degrade relevant enzymes involved in the mitosis of functional megaspores through the ubiquitin-proteasome pathway, promote the programmed death of egg cells, and eventually lead to reduction in seed setting rate. However, more data and in-depth studies are needed on how ESD1 affects the ubiquitination pathway and thus regulates the development of the embryo sac.

Subcellular localization analysis revealed that ESD1-GFP fusion proteins predominantly localized in the cytoplasm (Fig. 2B). There are 33 genes that encode the full-length OVATE domain containing proteins in the rice genome. Some of the OFP family members are generally located in the nuclei and function as transcription factors (Wang et al., 2008; Schmitz et al., 2015). Ovate family proteins are not a typical family of transcription factors. For example, the Arabidopsis ovate family proteins (AtOFPs) have been shown to function as transcriptional repressors (Wang et al., 2016c). In this study, we performed subcellular localization prediction for ESD1 protein with TargetP tools (http:/www.cbs.dtu.dk/services/TargetP/), and the result showed that ESD1 does not contain nuclear localization signal sequences (Supplemental Table S1). In addition to the subcellular localization study in rice protoplasts, we also repeated this experiment in tobacco, and the results showed that the fluorescent signal was distributed throughout the cell, including the nucleus and cytoplasm (Supplementary Figure S4), which indicated that ESD1 does not contain the typical nuclear localization signal peptide. Verification of ESD1 transcription activation showed that ESD1 was inactive in transcriptional activations. Therefore, we speculate that ESD1 might be an atypical transcription factor to regulate the development of embryo sac in rice, but a further investigation should be performed in the future study.

In conclusion, this study demonstrated that ESD1 positively regulates the seed setting rate by controlling embryo sac development in rice, and has implications for the improvement of rice yield. These results not only help to further illustrate the regulatory mechanism of embryo sac development but also have high theoretical value in revealing the molecular mechanism of rice grain formation.

\section{MATERIALS AND METHODS}




\section{Phylogenetic analysis of ESD1}

Protein sequence comparisons were conducted using MUSCLE v3.6 based on the BLAST given in TIGR (Rice Genome Annotation Project, http://rice.plantbiology.msu.edu/index.shtml) and PlantTFDB (Plant Transcription Factor Database, http://planttfdb.cbi.pku.edu.cn) of OFP family members. A phylogenetic tree was constructed with the aligned relative protein sequences using MEGA v3.0 (http://www.megasoftware.net/index. html) and Neighbor-Joining method with the following parameters: poisson correction, pairwise deletion, and bootstrap (1,000 replicates; random seed).

\section{Construction and transformation of CRISPR/Cas9 vectors}

We used CRISPR/Cas9 target site designing website called E-CRISP (http://www.e-crisp.org/E-CRISP/) to analyze and design the ESD1 sequences. Target sites TS1 and TS2 with high scores were selected to reduce the probability of missing shots. TS1, TS2, and their corresponding reverse complementary sequences were then made into 2 pairs of primers, TS1-U3-F/R and TS2-U6a-F/R (ggca and aaac were bound at the 5' ends of the forward primer and reverse primer respectively; Supplemental Table S2 for primer sequences). Through Golden Gate cloning, DS-TS1 and DS-TS2, the double-stranded sequences obtained by annealing the above two pairs of primers, were inserted into the intermediate vectors $p Y L g R N A-U 3$ and pYLgRNA-U6a, respectively. Two expression cassettes U3-TS1-gRNA and U6a-TS2-gRNA were obtained via PCR amplification (Supplemental Table S3 for the amplification primer sequences). Through Golden Gate cloning, two expression cassettes were then inserted into the plant expression vector $p Y L C R I S P R / C a s 9-M H$, after seedlings were obtained by tissue culture, primers SP1/SP2 were used to detect whether pYLCRISPR/Cas9-MH was introduced into the recipient plants (Supplemental Table S4 for primer sequences), and then primers ESD1-JC-F/R were used to amplify sequences containing the target sites TS1, TS2 (Supplemental Table S4 for the amplification primer sequences), and then sequencing was used to detect the mutations at the target sites.

\section{Microscopy of pollen grains}


Spikelet samples of 9522, esd1-m1, and esd1-m2 were collected from their main panicles (in the same position) 1 day before flowering, fixed in Kano solution (absolute ethanol: glacial acetic acid $=3$ : 1), and stored at $4^{\circ} \mathrm{C}$. For microscopic examination, each spikelet was stained with $1 \% \mathrm{I}_{2}-\mathrm{KI}$ and observed under a microscope with a $10 \mathrm{X}$ ocular. The field of view was switched at least 3 times. The total count of pollen grains was greater than 500. Judging criteria: the round dark brown pollen grains were considered fertile; irregularly shaped, weakly stained or unstained pollen grains were deemed sterile.

\section{Anther paraffin sections}

Spikelet samples at stage 8 of panicle development were taken from 9522, esd1-m1, and esd1-m2. Samples were dehydrated, hyalinized, immersed, and embedded in paraffin. Samples were then cut into $10 \mu \mathrm{m}$-thick sections, which were stained with safranin O-fast green, hyalinized, and sealed. The sections were observed under an Olympus BH2 optical microscope.

\section{Pollen grain culture in vitro}

An appropriate amount of liquid culture medium was placed on glass slides. When the plants were about to bloom, the spikelets of 9522, esd1-m1, and esd1-m2 were pinched with tweezers, after which their pollen grains were gently shaken off onto liquid media, respectively. The glass slides were covered with coverslips and placed in petri dishes with moistened filter paper. The petri dishes were sealed and incubated at $28^{\circ} \mathrm{C}$ in the dark for $60 \mathrm{~min}$. Afterward, a drop of $0.005 \%$ water-soluble aniline blue solution was added to each liquid culture medium, and the germination of pollens was checked under a fluorescence microscope. The above procedures were repeated three times for each group of samples. More than 200 pollen grains were detected each time. The average percentage of germinated pollens was deemed as the germination rate.

\section{Pollen tube germination test in vivo}

After heading, the flowering time of 9522, esd1-m1, and esd1-m2 was written down with a marker. Spikelet samples were collected at 0, 10, and $20 \mathrm{~min}$, and 1, 1.5, 2, and 
$2.5 \mathrm{~h}$ after flowering, fixed with FAA fixative for $24 \mathrm{~h}$, immersed in $70 \%$ ethanol solution and stored at $4^{\circ} \mathrm{C}$. The ovaries were peeled off before observation. The samples were then rehydrated in 50\%, 30\%, and 10\% ethanol (30 min each), washed with $\mathrm{ddH}_{2} \mathrm{O}$ two to three times, immersed in $2 \mathrm{~mol} / \mathrm{L} \mathrm{NaOH}$ solutions to soften for 12 $\mathrm{h}$, rinsed with $\mathrm{ddH}_{2} \mathrm{O}$ several times, stained with $0.05 \%$ aniline blue for $12 \mathrm{~h}$, and then observed under a confocal laser scanning microscope (Zeiss LSM 880).

\section{Saturation pollination}

One day before flowering, five individual plants sharing the same growth status among the esd1-m1 population were bagged. There were 2 panicles per bag and 2 bags per plant, one of which was used for saturation pollination, and the other for self-pollination. For saturation pollination, esd1-m1 plants were pollinated with 9522 pollens at the full-bloom stage. This process was repeated for seven consecutive days. Seeds were tested upon harvest, and the seed setting rate of saturation pollination and self-pollination were compared.

\section{Reciprocal cross tests}

The main panicle samples of 9522 and esd1-m1 were collected at the heading stage. Bloomed spikelets and spikelets that could not bloom on that day were cut off. The spikelets that could bloom on that day were retained and de-tasseled before flowering. At the full-bloom stage, de-tasseled spikelets of the esd1-m1 main panicles were pollinated with 9522 pollens, and de-tasseled spikelets of the 9522 main panicles were pollinated with esd1-m1 pollens. Seeds were tested upon harvest, and the seed setting rate of the two hybrids were compared (Li et al., 2011b).

\section{Tests for fertilization}

Spikelet samples were taken from 9522, esd1-m1, and esd1-m2 one day after flowering, and immersed in $40^{\circ} \mathrm{C}$ water overnight, followed by $35 \%$ concentrated hydrochloric acid for $30 \mathrm{~min}$. The residual hydrochloric acid was rinsed off with $\mathrm{ddH}_{2} \mathrm{O}$. The samples were then immersed in the $\mathrm{I}_{2}-\mathrm{KI}$ solution for an additional 30 min. After rinsing off the excess iodine with $70 \%$ alcohol, the samples were immersed in absolute ethanol for $30 \mathrm{~min}$. Lastly, the spikelets were hyalinized in xylene and 
examined on a fluorescent box.

468

469

470

471

472

473

474

475

476

477

478

479

480

481

482

483

484

485

486

487

488

489

490

491

492

493

494

495

496

\section{Mature embryo sac structure inspection}

Spikelet samples at stage 8 of panicle development were collected from 9522, esd1-m1, and esd1-m2, fixed with FAA fixative, and then immersed in $70 \%$ ethanol after ovaries were peeled off. In this process, the ovaries of different samples should be respectively immersed in ethanol at gradient concentrations $(50 \%, 30 \%$, and $15 \%)$ for $20 \mathrm{~min}$ each, and rinsed with $\mathrm{ddH}_{2} \mathrm{O} 2$ to 3 times. After that, the ovaries were hydrolyzed with $1 \mathrm{~mol} / \mathrm{L} \mathrm{HCl}$ in a $60^{\circ} \mathrm{C}$ water bath for $15 \mathrm{~min}$. Subsequently, the ovaries were stained with $1 \%$ eosin $\mathrm{Y}$ for $8 \mathrm{~h}$. After staining, the ovaries were rinsed with $\mathrm{ddH}_{2} \mathrm{O}$ until colorless and pre-treated with $0.1 \mathrm{~mol} / \mathrm{L}$ citric acid-disodium hydrogen phosphate buffer $(\mathrm{pH}=5.0)$ for $8 \mathrm{~h}$. They were then dyed with $20 \mu \mathrm{g} / \mathrm{ml}$ $\mathrm{H} 33342$ in the dark at $25^{\circ} \mathrm{C}$ for $24 \mathrm{~h}$. The ovaries were rinsed with $\mathrm{ddH}_{2} \mathrm{O} 2$ to 3 times and dehydrated in ethanol at gradient concentrations $(15 \%, 30 \%, 50 \%, 70 \%, 85 \%$, and $95 \%$ ) for $20 \mathrm{~min}$ each. The ovaries were then dehydrated twice with absolute ethanol for $2 \mathrm{~h}$ each time and transferred into absolute ethanol overnight. The next day, the dehydrated ovaries were immersed in a mixture of equal amounts of methyl salicylate and absolute ethanol for $1 \mathrm{~h}$ as a transition and then hyalinized with methyl salicylate three times. The first two times took $2 \mathrm{~h}$ each, and the last time took $15 \mathrm{~h}$, after which the ovaries could be stored in methyl salicylate. A drop of sesame oil was placed on each concave glass slide before observation, and a treated ovary was then mounted on a slide. After that, the slide was inverted under a confocal laser scanning microscope and scanned at $2 \mu \mathrm{m} /$ layer under $488 \mathrm{~nm}$ laser. Meanwhile, photographs were taken.

\section{qRT-PCR}

Total RNA was extracted using the TRIzol method, and cDNA was obtained by reverse transcription after digesting the RNA. The qRT-PCR reaction system (ABI QuantStudio 3) included: ESD1-qP-F/R primers (Supplemental Table S5 for primer

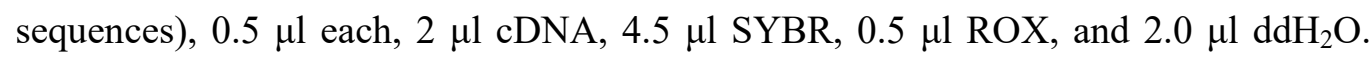
Three biological replicates and three technical replicates were taken. Settings for the qRT-PCR amplification program: $95^{\circ} \mathrm{C}$ for $5 \mathrm{~min} ; 95^{\circ} \mathrm{C}$ for $15 \mathrm{~s} ; 58^{\circ} \mathrm{C}$ for $35 \mathrm{~s} ; 45$ 
497 cycles; default settings for dissolution curve and cooling temperature. The internal reference standard was the expression level of OsACTIN1, and the expression of ESD1 was calculated using the $2^{-\Delta \Delta \mathrm{CT}}$ formula (Livak et al., 2001).

\section{In situ hybridization}

Roots, stems, leaves at the stage of panicle differentiation, and young panicles at stages 3-8 were taken (the whole process was guaranteed to be free of RNase contamination), fixed with FAA fixative, and then made into paraffin sections. ESD1-ish-F/R primers (Supplemental Table S6 for primer sequences) and in situ hybridization probes were designed for in vitro transcription. Kawata's experimental method was used for reference in the sensitivity test of the in situ probes (Kawata et al., 2010); Kouchi's experimental method was used for reference in the RNA hybridization and immunoassay (Kouchi et al., 1993).

\section{Subcellular localization in rice protoplast}

ESD1 and GFP fusion expression vector was constructed. A $10 \mu \mathrm{l}$ of fusion expression vector plasmid and $110 \mu \mathrm{l}$ of protoplasts were pipetted, placed in a $2 \mathrm{ml}$ centrifuge tube, and mixed well. A $130 \mu \mathrm{l}$ of $40 \%$ PEG4000 prepared on-site was added to the mixture, which was then let sit at room temperature for $15 \mathrm{~min} .500 \mathrm{ml}$ of W5 solution was added to stop the reaction, and the mixture was then centrifuged at $1188 \mathrm{rpm}$ for $2 \mathrm{~min}$, with the supernatant discarded. Then, $1 \mathrm{ml}$ of W5 solution was added to re-suspend the protoplasts. The mixture was again centrifuged at $1188 \mathrm{rpm}$ for $2 \mathrm{~min}$, with the supernatant discarded. Finally, $1 \mathrm{ml}$ of W5 solution (containing 1 $\mu \mathrm{l}$ of Kan) was added to re-suspend the protoplasts. The mixture was then transferred onto a 24-well plate, incubated at $28^{\circ} \mathrm{C}, 40 \mathrm{rpm}$ in the dark for $12-16 \mathrm{~h}$, and then observed under a confocal laser scanning microscope.

\section{Transcription activation verification}

The $p G B K T 7-E S D 1$ vector was constructed. $p$ GBKT7-CSA vector plasmid (positive control) and pGBKT7 empty vector plasmid (negative control) were used to transform Y2H Gold yeast competent cells using a heat shock approach. The bacterial solution was spread over the SD/-Trp solid medium, which was then sealed, inverted, and kept 
526 in an incubator at $28^{\circ} \mathrm{C}$ for $3-5 \mathrm{~d}$. Once the colonies reached $2-3 \mathrm{~mm}$, a single colony

527 from each of the 3 solid media was picked and diluted at 1:10,1:10 ${ }^{3}$, and 1:10 $.4 \mu 1$

528 of the diluents was transferred onto an SD/-Trp single-deficient plate and also onto an

$529 \mathrm{SD} /$-Trp-His-Ade triple-deficient plate. The plates were sealed, inverted, and kept in

530 an incubator at $30^{\circ} \mathrm{C}$ for 3-5 d after air-drying the bacterial plaques.

531

532

533

534

535

536

537

538

539

540

541

542

543

544

545

546

547

548

549

550

551

552

553

554

555

\section{Transcriptome analysis}

Extract and isolate mRNA from 9522, esd1-m1 plant young panicles at 5 and 6 stages of development, add crushing buffer, interrupt the mRNA into short sequences (200-700 nt), and then reverse transcribe to obtain double-stranded cDNA; purified, eluted, with base A added to the end and connected to the sequencing junction; and then enrich the cDNA library by PCR, with Illumina HiSeq 2000 sequenced the library. The sequences obtained after sequencing and filtering were compared to the reference genome of the Japonica variety Nipponbare.

\section{Accession Numbers}

Sequence data from this article for the cDNA and genomic DNA of ESD1 can be found in the GenBank/EMBL/Gramene data libraries under accession number LOC_Os10g29610.

\section{Supplemental Data}

The following supplemental materials are available.

Supplementary Figure S1. Phenotypic data of esd1-m3h.

Supplementary Figure S2. Effects of photoperiods on the fertility of esd1 mutants.

Supplementary Figure S3. Effects of temperature treatments on the fertility of esd1 mutants.

Supplementary Figure S4. The subcellular localization of ESD1 in tobacco.

Supplemental Table S1. Subcellular localization prediction for ESD1 protein with TargetP.

Supplemental Table S2. Amplification Primers for target sites TS1 and TS2.

Supplemental Table S3. Amplification primers for expression cassettes. 
556 Supplemental Table S4. Detection primers for target sites mutation.

557 Supplemental Table S5. Primers for qRT-PCR reaction.

558 Supplemental Table S6. Primers for in situ hybridization.

559

560 ACKNOWLEDGMENTS

561 We are grateful to Prof. Dabing Zhang, Shanghai Jiao Tong University for kindly

562 providing the microarray data. We are grateful to Prof. Yaoguang Liu, South China

563 Agricultural University for kindly providing the CRISPR/Cas9 editing vectors,

564 pYLgRNA-U3, pYLgRNA-U6a, and pYLCRISPR/Cas9-MH.

565

566 


\section{Parsed Citations}

Awasthi A, Paul P, Kumar S, Verma SK, Prasad R, Dhaliwa HS (2012) Abnormal endosperm development causes female sterility in rice insertional mutant OsAPC6. Plant Sci 183: 167-174

Google Scholar: Author Only Title Only Author and Title

Chang YX, Gong L, Yuan WY, Li XW, Chen GX, Li XH, Zhang QF, Wu CY (2009) Replication protein A(RPA1a) is required for meiotic and somatic DNA repair but is dispensable for DNA replication and homologous recombination in rice. Plant Physiol 151: 2162-2173

Google Scholar: Author Only Title Only Author and Title

Cheabu S, Moung-Ngam P, Arikit S, Vanavichit A, Malumpong C (2018) Effects of heat stress at vegetative and reproductive stages on spikelet fertility. Rice Sci 25: 218-226

Google Scholar: Author Only Title Only Author and Title

Fu J, Liu J, Cao ZQ, Wang ZQ, Zhang H, Yang JC (2014) Effects of alternate wetting and drying irrigation during grain filling on the seed-setting rate and grain weight of two super rice cultivars. Acta Agron Sin 40: 1056-1065

Google Scholar: Author Only Title Only Author and Title

Hackbusch J, Richter K, Muller J, Salamini F, Uhrig JF (2005) A central role of arabidopsis thaliana ovate family proteins in networking and subcellular localization of 3-aa loop extension homeodomain proteins. Proc Natl Acad Sci USA 102: $4908-4912$

Google Scholar: Author Only Title Only Author and Title

He YB, Yan L, Ge CN, Yao XF, Han X, Wang RC, Xiong LZ, Jiang LW, Liu CM, Zhao YD (2019) PINOID is required for formation of the stigma and style in rice. Plant Physiol 180: 926-936

Google Scholar: Author Only Title Only Author and Title

Hou JJ, Cao CH, Ruan YN, Deng YY, Liu YX, Zhang K, Tan LB, Zhu ZF, Cai HW, Liu FX, et al (2019) ESA1 is involved in embryo sac abortion in interspecific hybrid progeny of rice. Plant Physiol 180: 356-366

Google Scholar: Author Only Title Only Author and Title

Kawata A, Kubota S, Eguchi T, Moritani NH, Shimo T, Kondo S, Nishida T, Minagi S, Takigawa T (2010) Role of the low-density lipoprotein receptor-related protein-1 in regulation of chondrocyte differentiation. J Cell Physiol 222: 138-148

Google Scholar: Author Only Title Only Author and Title

Khanday I, Skinner D, Yang B, Mercier R, Sundaresan V (2019) Amale-expressed rice embryogenic trigger redirected for asexual propagation through seeds. Nature 565: 91-95

Google Scholar: Author Only Title Only Author and Title

Kou YJ, Chang YX, Li XH, Xiao JH, Wang SP (2012) The rice RAD51C gene is required for the meiosis of both female and male gametocytes and the DNA repair of somatic cells. J Exp Bot 63: 5323-5335

Google Scholar: Author Only Title Only Author and Title

Kouchi H, Hata S (1993) Isolation and characterization of novel nodulin cDNAs representing genes expressed at early stages of soybean nodule development. Mol Gen Genet 238: 106-119

Google Scholar: Author Only Title Only Author and Title

Kumar M, Basha PO, Puri A, Rajpurohit D, Randhawa GS, Sharma TR, Dhaliwal HS (2010) Acandidate gene OsAPC6 of anaphasepromoting complex of rice identified through T-DNAinsertion. Funct integr genomic 10: $349-358$

Google Scholar: Author Only Title Only Author and Title

Li DT, Chen LM, Jiang L, Zhu SS, Zhao ZG, Liu SJ, Su N, Zhai HQ, Ikehashi H, Wan JM (2007) Fine mapping of S32(t), a new gene causing hybrid embryo sac sterility in a Chinese landrace rice (Oryza sativa L.). Theor Appl Genet 114: 515-524

Google Scholar: Author Only Title Only Author and Title

Li EY, Wang SC, Liu YY, Chen JG, Douglas CJ (2011a) OVATE FAMILY PROTEIN4 (OFP4) interaction with KNAT7 regulates secondary cell wall formation in Arabidopsis thaliana. Plant J 67: 328-341

Google Scholar: Author Only Title Only Author and Title

Li M, Yu TF, Xu ZS, Zhang SX, Min DH, Chen M, Ma YZ, Chai SC, Zheng WJ (2017) Soybean Transcription Factor Gene GmNF-YCa Enhances Osmotic Stress Tolerance of Transgenic Arabidopsis. Acta Agron Sin 43: 1161-1169

Google Scholar: Author Only Title Only Author and Title

Li SC, Li WB, Huang B, Cao XM, Zhou XY, Ye SM, Li CB, Gao FY, Zou T, Xie KL, et al (2013) Natural variation in PTB1 regulates rice seed setting rate by controlling pollen tube growth. Nat Commun 4: 2793

Google Scholar: Author Only Title Only Author and Title

Li YB, Fan CC, Xing YZ, Jiang YH, Luo LJ, Sun L, Shao D, Xu CJ, Li XH, Xiao JH, et al (2011b) Natural variation in GS5 plays an important role in regulating grain size and yield in rice. Nat Genet 43: 1266-1269

Google Scholar: Author Only Title Only Author and Title

Liu CZ, Xue ZH, Tang DX, Shen Y, Shi WQ, Ren LJ, Du GJ, Li YF, Cheng ZK (2018) Ornithine ס-aminotransferase is critical for floret development and seed setting through mediating nitrogen reutilization in rice. Plant J 96: 842-854

Google Scholar: Author Only Title Only Author and Title 
Liu D, Sun W, Yuan YW, Zhang N, Hayward A, Liu YL, Wang Y (2014) Phylogenetic analyses provide the first insights into the evolution of OVATE family proteins in land plants. Ann Bot-London 113: 1219-1233

Google Scholar: Author Only Title Only Author and Title

Liu EB, Zeng SY, Zhu SS, Liu Y, Wu GC, Zhao KM, Liu XL, Liu QM, Dong ZY, Dang XJ, et al (2019) Favorable alleles of GRAN-FILLING RATE1 increase the grain-filling rate and yield of rice. Plant Physiol 181: 1207-1222

Google Scholar: Author Only Title Only Author and Title

Liu JJ, Zhang YY, Qin GJ, Tsuge T, Sakaguchi N, Luo G, Sun KT, Shi DQ, Aki S, Zheng NY, et al (2008) Targeted degradation of the cyclin-dependent kinase inhibitor ICK4/KRP6 by RING-Type E3 ligases is essential for mitotic cell cycle progression during

Arabidopsis Gametogenesis. Plant Cell 20: 1538-54

Google Scholar: Author Only Title Only Author and Title

Liu JP, Van Eck J, Cong B, Tanksley SD (2002) Anew class of regulatory genes underlying the cause of pear-shaped tomato fruit. Proc Natl Acad Sci USA 99: 13302-13306

Google Scholar: Author Only Title Only Author and Title

Liu XD, Xu XB, Lu YG, Xu SX (1997) The process of embryo formation and stages dividing in rice. Chin J Rice Sci 11: 141-150

Google Scholar: Author Only Title Only Author and Title

Livak KJ, Schmittgen TD (2001) Analysis of relative gene expression data using real-time quantitative PCR and the 2- $\Delta \Delta \mathrm{Ct}$ method. Methods 25: 402-408

Google Scholar: Author Only Title Only Author and Title

Luo Q, Tang D, Wang M, Luo WX, Zhang L, Qin BX, Shen Y, Wang KJ, Li YF, Cheng ZK (2013) The role of OsMSH5 in crossover formation during rice meiosis. Mol Plant 6: 729-742

Google Scholar: Author Only Title Only Author and Title

Ma SQ, Liu XH, Deng KC, Quan HJ, Tong LY, Xi ZX, Chai QR, Yang J (2018) Impact of low temperature in young ear formation stage on rice seed setting. Chin J Appl Ecol 29: 125-132

Google Scholar: Author Only Title Only Author and Title

Ma XL, Zhu QL, Chen YL, Liu YG (2016) CRISPR/Cas9 platforms for genome editing in plants: developments and applications. Mol Plant 9: $961-974$

Google Scholar: Author Only Title Only Author and Title

Ma XN, Zhang XY, Liu HM, Li ZH (2020) Highly efficient DNAfree plant genome editing using virally delivered CRISPR-Cas9. Nat Plants 6: $773-779$

Google Scholar: Author Only Title Only Author and Title

Ma YM, Yang C, He Y, Tian ZH, Li JX (2017) Rice OVATE family protein 6 regulates plant development and confers resistance to drought and cold stresses. J Exp Bot 68: 4885-4898

Google Scholar: Author Only Title Only Author and Title

Majumdar P, Karidas P, Siddiqi I, Nath U (2020) The ubiquitin-specific protease tni/ubp14 functions in ubiquitin recycling and affects auxin response. Plant Physiol 184: pp.00689.2020

Google Scholar: Author Only Title Only Author and Title

Pagnussat GC, Yu HJ, Sundaresan V (2007) Cell-fate switch of synergid to egg cell in arabidopsis eostre mutant embryo sacs arises from misexpression of the BEL1-like homeodomain gene BLH1. Plant Cell 19: 3578-3592

Google Scholar: Author Only Title Only Author and Title

Schmitz AJ, Begcy K, Sarath G, Walia H (2015) Rice Ovate Family Protein 2 (OFP2) alters hormonal homeostasis and vasculature development. Plant Sci 241: 177-188

Google Scholar: Author Only Title Only Author and Title

Selma S, Bernabé-Orts JM, Vazquez-Vilar M, Diego-Martin B, Ajenjo M, Garcia-Carpintero V, Granell A, Orzaez D (2019) Strong gene activation in plants with genome-wide specificity using a new orthogonal CRISPR/Cas9-based programmable transcriptional activator. Plant Biotechnol J 17: 1703-1705

Google Scholar: Author Only Title Only Author and Title

Si CL, Jin ZQ, Zheng JC, Tang RS (2018) Quantitative analysis on the effects of high temperature at meiosis stage on seed-setting rate of rice florets. Acta Agron Sin 34: 627-631

Google Scholar: Author Only Title Only Author and Title

Sun YW, Zhang X, Wu CY, He YB, Ma YZ, Hou H, Guo XP, Du WM, Zhao YD, Xia LQ (2016) Engineering herbicide-resistant rice plants through CRISPR/Cas9-mediated homologous recombination of acetolactate synthase. Mol Plant 9: 628-631

Google Scholar: Author Only Title Only Author and Title

Tang D, Miao CB, Li YF, Wang HJ, Liu XF, Yu HX, Cheng ZK (2014) OsRAD51C is essential for double-strand break repair in rice meiosis. Front Plant Sci 5: 167

Google Scholar: Author Only Title Only Author and Title 
Toh S, Kamiya Y, Kawakami N, Nambara E, McCourt P, Tsuchiya Y (2012) Thermoinhibition uncovers a role for strigolactones in arabidopsis seed germination. Plant Cell Physiol 53: 107-117

Google Scholar: Author Only Title Only Author and Title

Tokumaru M, Adachi F, Toda M, Ito-Inaba Y, Yazu F, Hirosawa Y, Sakakibara Y, Suiko M, Kakizaki T, Inaba T (2017) UbiquitinProteasome dependent regulation of the GOLDEN2-LIKE 1 transcription factor in response to plastid signals. Plant Physiol 173: 524535

Google Scholar: Author Only Title Only Author and Title

Wang C, Liu Q, Shen Y, Hua YF, Wang JJ, Lin JR, Wu MG, Sun TT, Cheng ZK, Mercier R, et al (2019) Clonal seeds from hybrid rice by simultaneous genome engineering of meiosis and fertilization genes. Nat Biotechnol 37: 283-286

Google Scholar: Author Only Title Only Author and Title

Wang CL, Wang Y, Cheng ZJ, Zhao ZG, Chen J, Sheng PK, Yu Y, Ma WW, Duan EC, Wu FQ, et al (2016a) The role of OsMSH4 in male and female gamete development in rice meiosis. J Exp Bot 67: 1447-1459

Google Scholar: Author Only Title Only Author and Title

Wang LZ, Wang LM, Xiang HT, Luo Y, Li R, Li ZJ, Wang CY, Meng Y (2016b) Relationship of photosynthetic efficiency and seed-setting rate in two contrasting rice cultivars under chilling stress. Photosynthetica 54: 581-588

Google Scholar: Author Only Title Only Author and Title

Wang N, Huang HJ, Ren ST, Li JJ, Sun Y, Sun DY, Zhang SQ (2012) The Rice Wall-Associated Receptor-Like Kinase Gene OsDEES1 Plays a Role in Female Gametophyte Development. Plant Physiol 160: 696-707

Google Scholar: Author Only Title Only Author and Title

Wang SC, Chang Y, Ellis B (2016c) Overview of OVATE FAMILY PROTEINS, a novel class of plant-specific growth regulators. Front Plant Sci 7: 417

Google Scholar: Author Only Title Only Author and Title

Wang Y, Diehl A, Wu FN, Vrebalov J, Giovannoni J, Siepel A, Tanksley SD (2008) Sequencing and comparative analysis of a conserved syntenic segment in the solanaceae. Genetics 180: 391-408

Google Scholar: Author Only Title Only Author and Title

Wang YK, Chang WC, Liu PF, Hsiao MK, Lin CT, Lin SM, Pan RL (2010) Ovate family protein 1 as a plant Ku70 interacting protein involving in DNA double-strand break repair. Plant Mol Biol 74: 453-466

Google Scholar: Author Only Title Only Author and Title

Xia FN, Zeng BQ, Liu HS, Qi H, Xie LJ, Yu LJ, Chen QF, Li JF, Chen YQ, Jiang LW, et al (2020) SINAT E3 Ubiquitin Ligases Mediate FREE1 and VPS23A Degradation to Modulate Abscisic Acid Signalling. Plant Cell 32: tpc.00267.2020

Google Scholar: Author Only Title Only Author and Title

Xiang XJ, Zhang PP, Yu P, Zhang YX, Yang ZF, Sun LP, Wu WX, Khan RM, Abbas A, Cheng SH, et al (2019) LSSR1 facilitates seed setting rate by promoting fertilization in rice. Rice 12: 31

Google Scholar: Author Only Title Only Author and Title

Xiao YH, Liu DP, Zhang GX, Tong HN, Chu CC (2017) Brassinosteroids regulate OFP1, a DLT interacting protein, to modulate plant architecture and grain morphology in rice. Front Plant Sci 8: 1698

Google Scholar: Author Only Title Only Author and Title

Xu M, Tang DX, Cheng XJ, Zhang JX, Tang YJ, Tao QD, Shi WQ, You AQ, Gu MH, Cheng ZK (2019) OsPINOID regulates stigma and ovule initiation through maintenance of the floral meristem by auxin signaling. Plant Physiol 180: $952-965$

Google Scholar: Author Only Title Only Author and Title

Xu XJ, Li B, Liu SY, Zhang GL (2014) Effects of high temperature stress at heading stage on flowering habits and seed-setting rate in rice. Hybrid Rice 29: 57-62

Google Scholar: Author Only Title Only Author and Title

Xu Y, Wang FQ, Chen ZH, Wang J, Li WQ, Fan FJ, Tao YJ, Jiang YJ, Zhu QH, Yang JZ (2020) CRISPR/Cas9-targeted mutagenesis of the OsROS1 gene induces pollen and embryo sac defects in rice. Plant Biotechnol J 18: 1999-2001

Google Scholar: Author Only Title Only Author and Title

Xu Y, Yang J, Wang YH, Wang JC, Yu Y, Long Y, Wang YL, Zhang H, Ren YL, Chen J, et al (2017) OsCNGC13 promotes seed-setting rate by facilitating pollen tube growth in stylar tissues. PLoS Genet 13: e1006906

Google Scholar: Author Only Title Only Author and Title

Yang C, Shen WJ, He Y, Tian ZH, Li JX (2016) OVATE family protein 8 positively mediates brassinosteroid signaling through interacting with the GSK3-like kinase in rice. PLoS Genet 12: e1006118

Google Scholar: Author Only Title Only Author and Title

Zee SY (1997) Changes in the pattern of organization of microtubules in the embryo sac of rice. Plant Physiol $114: 248$

Google Scholar: Author Only Title Only Author and Title

Zhang HW, Si XM, Ji X, Fan R, Liu JX, Chen KL, Wang DW, Gao CX (2018) Genome editing of upstream open reading frames enables translational control in plants. Nat Biotechnol 36: 894-898 
Google Scholar: Author Only Title Only Author and Title

Zhang L, Tang D, Luo Q, Chen XJ, Wang HJ, Li YF, Cheng ZK (2014) Crossover formation during rice meiosis relies on interaction of OsMSH4 and OsMSH5. Genetics 198: 1447-1456

Google Scholar: Author Only Title Only Author and Title

Zhang Q, Zhang Y, Lu MH, Chai YP, Jiang YY, Zhou Y, Wang XC, Chen QJ (2019) Anovel ternary vector system united with morphogenic genes enhances CRISPR/Cas delivery in maize. Plant Physiol 181: 1441-1448

Google Scholar: Author Only Title Only Author and Title

Zhang ZY, Li JH, Li F, Liu HH, Yang WS, Chang K, Xu YY (2017) OsMAPK3 phosphorylates OsbHLH002/OsICE1 and inhibits its ubiquitination to activate OsTPP1 and enhances rice chilling tolerance. Dev Cell 43: 731-743

Google Scholar: Author Only Title Only Author and Title

Zhou SR, Wang Y, Li WC, Zhao ZG, Ren YL, Wang Y, Gu SH, Lin QB, Wang D, Jiang L, et al (2011) Pollen semi-sterility1 encodes a kinesin-1-like protein important for male meiosis, anther dehiscence, and fertility in rice. Plant Cell 23: 111-129

Google Scholar: Author Only Title Only Author and Title 